\title{
Significant improvement of systolic function after pulmonary vein isolation by cryoablation - a case report
}

\author{
DBarbara Rubinićc ${ }^{*}$, \\ Dibia Dubravčić², \\ (D)Hrvoje Jurin², \\ DDaniel Lovrić \\ DBorka Pezo-Nikolić², \\ DMislav Puljević², \\ (D) Vedran Velagić ${ }^{2}$, \\ DDavor Puljević ${ }^{2}$
}

'University of Zagreb School of Medicine, Zagreb, Croatia

${ }^{2}$ University of Zagreb School of Medicine, University Hospital Centre Zagreb, Zagreb, Croatia

RECEIVED:

December 3, 2020

ACCEPTED:

December 18, 2020

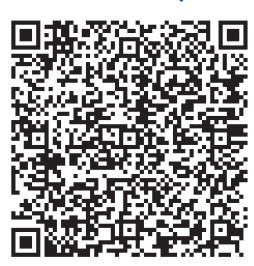

$\square$ Cardiologia Croatica 2021;16(1-2):16.

\begin{abstract}
KEYWORDS: atrial fibrillation, cryoablation, heart failure, pulmonary vein isolation. CITATION: Cardiol Croat. 2021;16(1-2):16. | https://doi.org/10.15836/ccar2021.16
\end{abstract}

*ADDRESS FOR CORRESPONDENCE: Barbara Rubinić, Medicinski fakultet Sveučilišta u Zagrebu, Šalata 3, HR-10000 Zagreb, Croatia. / Phone: +385-98-9884117 / E-mail: barbara.rubinic@gmail.com

ORCID: Barbara Rubinić, https://orcid.org/0000-0003-2592-6427 • Mia Dubravčić, https://orcid.org/0000-0003-0441-4772 Hrvoje Jurin, https://orcid.org/0000-0002-2599-553X • Daniel Lovrić, https://orcid.org/0000-0002-5052-6559 Borka Pezo-Nikolić, https://orcid.org/0000-0002-0504-5238 • Mislav Puljević, https://orcid.org/0000-0003-1477-2581 Vedran Velagić, https://orcid.org/0000-0001-5425-5840 • Davor Puljević, https://orcid.org/0000-0003-3603-2242

\section{|||||||||||||||||||||||||||||||||||||||||||||||||||||||||||||||||||||||||||||||||||||||||||||||||||||||||||||||||||||||||||||||||||||}

Introduction: Atrial fibrillation can lead to heart failure with reduced ejection fraction (HFrEF) by reducing cardiac output due to irregular rhythm, high frequency of the ventricles, reducing diastole time and loss of atrial contraction. HFrEF could also potentiate the onset of atrial fibrillation due to the increase of pressure in the left atrium, enlargement of the left atrium, activation of the sympathetic nervous system which in turn can potentiate automatic triggers and functional mitral regurgitation. ${ }^{1}$

Case report: We present 47-year old male who was physically active, playing amateur football. On routine check-ups persistent normofrequent atrial fibrillation was found along with dilation of all four chambers. Patient complained of exertion fatigue, dyspnea on exertion and feeling of an irregular heart rhythm. Transthoracic echocardiography revealed diffuse hypocontractility and severe reduction in systolic function of the left ventricle, with ejection fraction (EF) of 35\%. Coronary artery disease was excluded. Automatic cardioverter defibrillator (AICD) was implanted in primary prevention of sudden cardiac death. Two and a half years later systolic function has improved (EF 50\%) and there was a spontaneous conversion to sinus rhythm. AICD was explanted on patient request. Less than a year after, systolic function has once again declined (EF 20\%) and a recurrence of persistent atrial fibrillation with average heart rate obtained in Holter ECG 90/min was observed. After the recurrence of arrhythmia post electrocardioversion, pulmonary vein isolation with cryoablation was performed. Eight and 17 months after the ablation no recurrence of atrial fibrillation was found. Patient is again physically active (jogging) and ejection fraction returned to normal.

Conclusion: Atrial fibrillation and heart failure with their pathophysiological mechanisms can make the "circulus vitiosus". This case report shows how removal of arrhythmogenic triggers, normalization of the heart rhythm and heart rate could significantly contribute to the improvement of heart function. That could be explained by halting, and possibly even reverting, the structural and electrical heart remodeling.
LITERATURE IIIIIIIIIIIIIIIIIIIIIIIIIIIIIIIIIIIIIIIIIIIIIIIIIIIIIIIIIIIIIIIIIIIIIIIIIIIIIIIIIIIIIIIIIIIIIIIIIII

1. Verma A, Kalman JM, Callans DJ. Treatment of Patients With Atrial Fibrillation and Heart Failure With Reduced Ejection Fraction. Circulation. 2017 Apr 18:135(16):1547-1563. https://doi.org/10.1161/CIRCULATIONAHA.116.026054 